\title{
Business model innovation and strategic transformation when confronting digital disruption: The case of data- driven business models for professional services
}

\section{Erwin Fielt}

School of Information Systems

Queensland University of Technology

Brisbane, Australia

Email: e.fielt@qut.edu.au

\section{Peter Westerveld}

School of Information Systems

Queensland University of Technology

Brisbane, Australia

Email: peter.westerveld@hdr.qut.edu.au

\section{Kevin Desouza}

School of Management

Queensland University of Technology

Brisbane, Australia

Email: kevin.desouza@qut.edu.au

\section{Guy Gable}

School of Information Systems

Queensland University of Technology

Brisbane, Australia

Email: g.gable@qut.edu.au

\begin{abstract}
Most businesses and industries are undergoing significant disruption due to digital innovation. We focus our discussion on the rise of data-driven business models in the professional services industry. Big data, advanced analytics and artificial intelligence solutions are now diffusing across industries. Professional services firms are knowledge-intensive which may raise specific issues in relation to data analytics and artificial intelligence. In addition, these firms currently face high levels of potential disruption due to digital innovation by new start-ups. When trying to understand the impact of these developments on the professional services industry, two prominent issues need to be considered. Firstly, digital innovation often results in the creation of new business models. This raises questions about whether these models are more generic (digital), showing great similarities across industries, or specific to the professional services industry. Moreover, there are questions related to whether the initiators of business model innovation are new, digital start-ups, or well-established incumbents. Secondly, when an incumbent is required to transform due to digital disruption, we need a more nuanced understanding of the strategic transformation processes in relation to the nature of professional services and technology innovation. Our paper makes two major contributions to the literature. First, it takes a critical look at data-driven business models in the context of professional services firms. Second, it puts forth several research propositions that warrant further critical examination when it comes digital disruption barriers and enablers faced by incumbents and start-ups.
\end{abstract}

Keywords: Digital innovation, data-driven, professional services firms, business model innovation, strategic transformation. 


\section{Introduction}

The ongoing proliferation of digital technologies, such as mobile technology, cloud computing, data analytics, and internet of things, is changing the way people live their lives, transforming the way organizations conduct their business, and creating new kinds of services and products. The World Economic Forum states that 'the future of countries, businesses, and individuals will depend more than ever on whether they embrace digital technologies' (Baller et al. 2016, p. v). These new digital technologies, and the disruptive innovations they enable and drive, often require novel, digital business models (Fichman et al. 2014). Business model innovation (Foss and Saebi 2017; Massa and Tucci 2014), which is targeting new ways for organizations to create and capture customer value (Chesbrough 2006; Fielt 2013), has become a prominent theme in the digital age. However, digital business model innovation and its relation with organization transformation is not well understood (DaSilva et al. 2013). Only a few studies have been conducted so far (e.g., Westerman et al. 2014) and these often do not address the specific challenges of business model innovation nor do they focus on particular industries, like professional services.

The objective of this paper is to examine business model innovation for digital innovation by looking at the specific case of data-driven business models in the professional services industry. Professional services firms (e.g., management consulting, accounting, legal, finance, etc.) are knowledge-intensive, which may raise specific issues in relation to how data analytics and machine learning innovations impact their operational and strategic postures. In addition, these firms currently face high levels of potential disruption due to digital innovations by new start-ups, frequently labelled nowadays as LegalTech, HR Tech, Accounting Tech, FinTech, etc. According to the World Economic Forum (2017, p. 4), "professional services appears to be approaching a tipping point, as disruptive technologies drive fundamental changes in the industry's economics."

When trying to understand the impact of digital innovation due to data analytics and artificial intelligence on the professional services industry, two prominent issues need to be considered. Firstly, digital innovation often results in the creation of new business models. This raises questions about whether these models are more generic (digital), showing great similarities across industries, or specific to the professional services industry. Moreover, there are questions related to whether the initiators of business model innovation are new, digital start-ups, or well-established incumbents. Secondly, when an incumbent is required to transform due to digital disruption, we need a more nuanced understanding of the strategic transformation processes.

The remainder of this research-in-progress paper is structures as follows. First we provide a brief overview of data-driven business models and the professional services industry. Next we explore some initial ideas for business model innovation and strategic transformation when confronting digital disruption. We end with presenting our concluding remarks and future research.

\section{Data-driven business models and the professional services industry}

With the advances of big data, analytics and algorithms (Chen et al. 2012; Günther et al. 2017; Newell and Marabelli 2015), business models have become data-driven (Hartmann et al. 2016). Data-driven business models are shaped by critical data-driven elements. Data is the key resource, the process of turning data into value as key activity, data-enriched or data-driven products and services as value proposition, and monetize data as revenue stream (Hartmann et al. 2016; Schüritz et al. 2017; Wixom and Ross 2017). Hartmann et al. (2016) have identified six types of data-driven business models differentiated by key data source and key data activity based on an empirical analysis of start-ups. Firms often have different options when it comes to creating data-driven business models. For example, the Climate Corporation started with using data analytics for providing weather insurance to agriculture firms as opposed to providing weather forecasting and planning services ${ }^{1}$. Next it moved out of the weather insurance and became a digital agriculture platform that supports agriculture firms to make data-driven decisions to maximize their return².

Firms can use data, analytics and algorithms to improve and/or innovate (or disrupt) their business model (Günther et al. 2017; Loebbecke and Picot 2015; Woerner and Wixom 2015). To improve their business model, firms can use data, analytics and algorithms to refine and optimize their business

\footnotetext{
${ }^{1}$ Retrieved from http://www.climate.com/growers/total-weather-insurance/ [7/9/2012]

2 Retrieved from https://climate.com/about [25/7/2018]
} 
processes and decision making (Woerner and Wixom 2015). To innovate their business model, firms can use data, analytics and algorithms to find new ways of generating revenues, enter new markets, and even explore new sources of competitive advantage through strategic renewal via data monetization and digital transformation (Woerner and Wixom 2015). According to a study from McKinsey (Chin et al. 2017), analytics can create new opportunities and disrupt entire industries. For example, some companies are now charging for the analytics-enabled service rather than directly selling the product. (e.g., Rolls-Royce's 'Power-by-the-Hour'). Günther et al. (2017) note that improvement and innovation approaches can be mixed and even happen in sequence. Loebbecke and Picot (2015) warn that traditional firms may fail to benefit from big data analytics as the improvement of business models will not be enough for lasting competitive advantage due to the commodization of big data 'solutions' and the innovation of business models may be a struggle for these firms when established business models get disrupted. The identification of appropriate approaches to take advantage of emerging digital technologies is concern faced by non-profit (Desouza and Smith 2014) and public agencies (Desouza and Jacob 2017) as well.

The professional services industry has emerged as one of the most rapidly growing, profitable, and significant sectors of the global economy (Empson et al. 2015). Professional services firms are knowledge intensive organizations that facilitate economic and commercial exchange by providing advice to business (Greenwood et al. 2006). They are comprised primarily of professionals and their key resources are intellectual capital and expertise. Empson et al. (2015) state that professional services firms are defined by four characteristics they all possess, to varying degrees: (1) the primary activity of applying specialist knowledge to create customized solutions to clients' problems, (2) specialist technical knowledge of professionals and in-depth knowledge of their clients as core assets, (3) governance arrangements with extensive individual autonomy and contingent managerial authority, where core producers own or control core assets, and (4) an identity where core producers recognize each other as professionals and are recognized as such by clients and competitors. Maister (1993) notes that professional services firms perform three types of work: (1) procedural work for which the solution/approach is (mostly) well-known and the focus is on efficiency, (2) grey hair work requiring skills and experience and (3) brain work requiring expertise and innovation.

With the increasing availability and access to data for anyone ('data democratization') and new ways of creating and leveraging knowledge (e.g., crowdsourcing), the strategic position of these firms as gatekeepers is potentially under threat. For example, in the legal service industry, established firms are confronted with new start-ups that are introducing new digital services such as legal decision predictions (e.g., Case Crunch3) and 'robot lawyers' (e.g., DoNotPay4). Data-driven business model for professional services firms may be different from other industries due to its specific characteristics, as noted above, and how data and technology play a role in the industry. For example, in some professional service industries there is data which is a shared resource. Take the legal service industry where predictive models have been developed that predict the behaviour of the Supreme Court of the United States, based on historical Supreme Court justice votes and case data (Katz et al. 2017). Moreover, today's technologies such as machine learning and the availability of databases is making it possible for new innovations (e.g. digital agents), autonomous tools to fill legal forms and even provide recommendations for simple queries and tasks.

\section{Exploring ideas for business model innovation and strategic transformation}

When trying to understand the impact of digital disruption on the professional services industry, we propose that two prominent issues need to be considered based on our preliminary analysis. First, digital innovation often comes with new business models. This raises questions about whether these models are more generic (digital), showing great similarities across industries, or specific to the particular professional services industry. Moreover, there are questions related to whether the initiators of business model innovation are new, digital start-ups, or well-established incumbents. Second, when an incumbent is required to transform due to digital disruption, we need a more nuanced understanding of the strategic transformation processes in relation to the nature of professional services and technology innovation. Below we will further elaborate these preliminary ideas and develop some possible scenarios for business model innovation and strategic transformation.

3 See https://www.case-crunch.com/

4 See https://www.donotpay.com/ 
Starting-point for our reasoning is that digital disruption often come with new, digital business models (Fichman et al. 2014; Fielt and Gregor 2016). The disruptive impact of digital technologies on the business models of different industries is substantially highlighted in practitioner publications (e.g., Deloitte Australia 2012; Deloitte Australia 2014) and as such this could indicate that there is a need for more specific academic research in this area. The new, digital business models often rise to prominence in one or a few industries and from there spread to other industries. For example, the notion of crowdsourcing via digital platforms (McAfee and Brynjolfsson 2017) came to prominence in the late 1990 s and early 2000s via examples like SETI@ home, Wikipedia, and Innocentive. In the last years, we have seen crowdsourcing being introduced for legal services (e.g., Legal Services Link) and strategy consulting (e.g., Deloitte). The question rises if these models will work there too and if so, to what extent they may need to be adapted to the specific opportunities and threats of the industry and strengths and weaknesses of the firm.

When a particular industry is confronted with new business models due to digital disruption, we see two possible choices with respect to the new business models themselves as well and the initiators of these models based on ideas from, amongst others, Chesbrough (Chesbrough 2010; Chesbrough and Rosenbloom 2002), Christensen (Christensen 1997; Christensen and Raynor 2003) and Govindarajan and Trimble (2005; 2010). Firstly, the new business models themselves can be more generic, showing great similarities across industries, or be specific to a particular industry or organization. The generic business models emphasize the new idea (e.g., crowdsourcing) and the digital innovations enabled by digital technologies (e.g., easy access, automatic matching, global reach) as proven by their (initial) successful application in other industries. The specific business models will tap into proven practices and arrangements of the particular industry or even organization, which will result in major adaptions of the digital business model or even reinventing it. This will make the business model less disruptive, which can be both advantageous (as it is more aligned to the existing operating environment and strategic framework and will encounter less resistance) as well as disadvantageous (as it will less likely offer radical new benefits or appeal to new customers).

Secondly, the initiators of business model innovation in a particular industry can be new, digital startups or well-established incumbents. Existing professional services firms (e.g. McKinsey, Accenture, etc.) have key resources like their brand name, human capital, knowledge, project/matter/client databases and expertise that they can leverage in a digital world. However, other characteristics, like their traditional business model and their specific organizational form (partnership model), may hinder them in adapting to digital disruption. For example, when the professional logic (i.e., the interpretive schemes or institutional logics of a profession) is strong, professionals can be highly risk averse (Barratt and Hinings 2015). Moreover, they may have trouble in acquiring or integrating the digital capabilities required. While new start-ups may lack some of the reputation and brand recognition when compared to the incumbents, they do have the opportunity to access human and intellectual capital in the specific industry and then scale it through digital platforms that support intellectual asset re-use (Davenport et al. 2003), personalized delivery of knowledge resources and automated learning systems to predict and respond to future service needs.

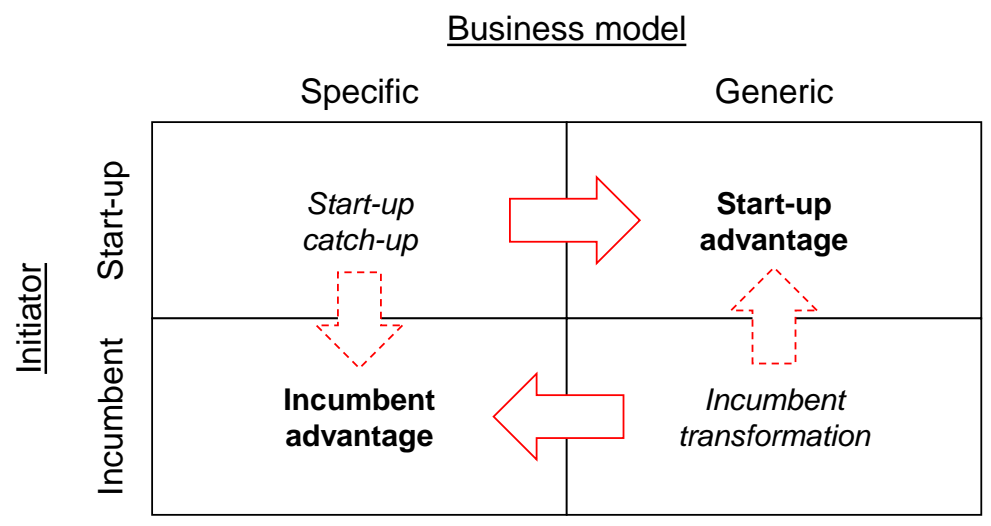

Figure 1: Business model innovation scenarios.

Looking across the new business models and the initiators of these models, we see 4 possible strategic positions as presented in Figure 1. We tentatively propose that when digital business models are more specific for the industry then the incumbents will more likely have a competitive advantage. In this case the strengths of incumbents are well aligned with some of the key characteristics of the digital business model. We also tentatively propose that when digital business models are more generic across industries 
then the start-ups will more likely have a competitive advantage. The digital start-ups will benefit from their greenfield approach and their agility while the incumbents are hindered by their dominant logic and technological legacy (e.g., tech debt). Moreover, the uptake of new digital initiative may be hindered by the traditional business due to fear of revenue cannibalization.

In addition, we suggest that when the incumbent has a disadvantage, they need to transform and either find ways to leverage of their existing strengths and/or tap into the start-up advantage. This creates a paradox for the incumbent as these point to opposite approaches. On the one hand, they will be pulled towards finding ways to try to integrate their new data-driven initiative with their existing business, while on the other hand they will be pulled towards differentiating their new data-driven initiative from their existing business. When the start-up has a disadvantage, they need to catch-up with existing strengths of incumbents and either need to find ways to tap into the incumbent advantage and/or leverage start-up advantages. This creates a paradox for the start-up as these point to opposite approaches. On the one hand, they will be pulled towards collaborating with incumbents while on the other hand they will be pulled towards competing with them head on.

We are especially interested in the strategic transformation of incumbent professional services firms. While some general advice is available in relation to disruptive innovation (Christensen 1997; Christensen and Raynor 2003) and strategic innovation (Govindarajan and Trimble 2005), these approaches do not cover the knowledge-intensive nature of professional services nor the dynamics of technology innovation. As such, we intend to look deeper into how these two factors play a role in the strategic transformation as professional services firms come in a wide assortment of forms (Figure 2). As such, we may expect that their transformation approaches and barriers may depend on this. A critical dimension to classify these firms (or their business units) is in respect to their dependence on existing knowledge assets. A firm with high dependence on existing knowledge assets will have established high barriers to entry for their competitors. As an example, firms offering consulting services in the defence and security arena would meet these criteria. These firms depend on decades on knowledge assets that include social capital, prior project experiences, and specialized know-how that is not easy to acquire on the market instantly. A firm with low dependence on existing knowledge assets will need to continuously innovate to stay ahead of its competitors by keeping its knowledge assets fresh and relevant. Let us be clear, we are not arguing that a firm's existing knowledge assets are of no value. What we are saying that is that in order for the firm to compete, they cannot use their dependence on their existing knowledge assets as a measure of how insulated they are from competitor's actions (due to the history, costs, or resources required to acquire or replicate the knowledge).

With respect to the dynamics of technology innovation, IT can be an operational capability or a strategic (dynamic, improvisational) capability (Pavlou and El Sawy 2010). Of particular importance is that a strategic IT capability can support organizations with the transformation in moderately to highly turbulent environments. In addition, the IT architecture of the organization will also determine to which extent an organization can evolve and integrate new IT-based solutions (Alwadain et al. 2016). Figure 2 depicts a simple matrix that can be used to map professional services firms on the two dimensions. We expect that the more depended a professional services firm is on industry-specific knowledge assets the more complex and unique the technology and implementation of technological innovation required. And therefore, the more dynamic the role and capability of technology will need to be. The less dependent on industry-specific knowledge assets will allow for a more repeatable and less complex process driven approach where a less strategic but more continuous improvement role and technology capability is required.

Dependence on Industry-Specific Knowledge Assets

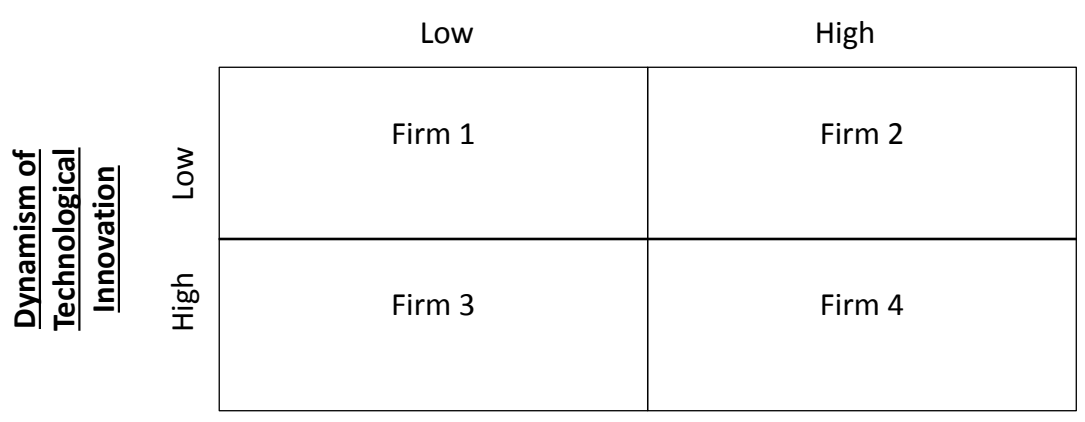

Figure 2: Strategic transformation scenarios. 


\section{Concluding remarks and future research}

In this research-in-progress paper, we focussed on business model innovation and strategic transformation when professional services firms are confronting digital disruption driven by big data, advanced analytics and artificial intelligence. We in particular are interested in the barriers and enablers for incumbents and start-ups and the influence of industry-specific knowledge assets and technology innovation. We elaborate our preliminary ideas with the purpose of exploring this topic, not so predefining a theoretical framework.

For our future work, we propose to study business model innovation and strategic transformation in relation to the rise of data-driven business models within the legal services industry. This study will focus on the B2B legal market segment which typically operates in the higher value part of the legal professional services market, have a higher dependency on more complex knowledge assets and prior project experience and does not fit the more typical B2C digital disruption models. As a first study, we plan to do a multiple case study with one large international traditional law firm, one medium sized traditional national law firm and one new start-up law firm. This study has the objective to answer the question to what extent data-driven business model dimensions are already present (as-is) and compare incumbent traditional model law firms across different geographic footprint and size with a start-up firm in this context. In addition, we plan to compare out initial insights with the ideas and opinions of industry experts by performing a Delphi study in order to answer the question what the future opportunities of a data-driven business model for B2B law firms could be.

\section{References}

Alwadain, A., Fielt, E., Korthaus, A., and Rosemann, M. 2016. "Empirical Insights into the Development of a Service-Oriented Enterprise Architecture," Data \& Knowledge Engineering (105), pp. 3952.

Baller, S., Dutta, S., and Lanvin, B. (eds.). 2016. The Global Information Technology Report 2016: Innovating in the Digital Economy. Geneva: World Economic Forum.

Barratt, M., and Hinings, B. 2015. "Service Innovation in Professional Service Firms: A Review and Future Research Directions," in The Oxford Handbook of Professional Service Firms, L. Empson, D. Muzio, J. Broschak and B. Hinings (eds.). Oxford, UK: Oxford University Press pp. 238-254.

Chen, H., Chiang, R. H. L., and Storey, V. C. 2012. "Business Intelligence and Analytics: From Big Data to Big Impact " MIS Quarterly (36:4), pp. 1165-1188.

Chesbrough, H. 2006. Open Business Models: How to Thrive in the New Innovation Landscape. Boston, MA: Harvard Business School Press.

Chesbrough, H. 2010. "Business Model Innovation: Opportunities and Barriers," Long Range Planning (43:2-3), pp. 354-363.

Chesbrough, H., and Rosenbloom, R. S. 2002. "The Role of the Business Model in Capturing Value from Innovation: Evidence from Xerox Corporation's Technology Spin-Off Companies," Industrial and Corporate Change (11:3), pp. 529-555.

Chin, J. K., Hagstroem, M., Libarikian, A., and Rifai, K. 2017. "Advanced Analytics: Nine Insights from the C-Suite," McKinsey \& Company.

Christensen, C. M. 1997. The Innovator's Dilemma: When New Technologies Cause Great Firms to Fail. Boston, MA Harvard Business School Press.

Christensen, C. M., and Raynor, M. E. 2003. The Innovators Solution: Creating and Sustaining Successful Growth. Boston, MA: Harvard Business School Press.

DaSilva, C. M., Trkman, P., Desouza, K., and Lindič, J. 2013. "Disruptive Technologies: A Business Model Perspective on Cloud Computing," Technology Analysis \& Strategic Management (25:10), pp. 1161-1173.

Davenport, T. H., Thomas, R. J., and Desouza, K. C. 2003. "Reusing Intellectual Assets," Industrial Management (45:3), pp. 12-13.

Deloitte Australia. 2012. "Digital Disruption: Short Fuse, Big Bang?," Deloitte Touche Tohmatsu.

Deloitte Australia. 2014. "Digital Disruption - Harnessing the 'Bang': Stories from the Digital Frontline," Deloitte Touche Tohmatsu.

Desouza, K. C., and Jacob, B. 2017. "Big Data in the Public Sector: Lessons for Practitioners and Scholars," Administration \& Society (49:7), pp. 1043-1064.

Desouza, K. C., and Smith, K. L. 2014. "Big Data for Social Innovation," Stanford Social Innovation Review (12:3), pp. 39-43.

Empson, L., Muzio, D., Broschak, J., and Hinings, B. 2015. "Researching Professional Service Firms: An Introduction and Overview," in The Oxford Handbook of Professional Service Firms, L. 
Empson, D. Muzio, J. Broschak and B. Hinings (eds.). Oxford, UK: Oxford University Press pp. 1-22.

Fichman, R. G., Dos Santos, B. L., and Zheng, Z. E. 2014. "Digital Innovation as a Fundamental and Powerful Concept in the Information Systems Curriculum," MIS Quarterly (38:2), pp. 329-353.

Fielt, E. 2013. "Conceptualising Business Models: Definitions, Frameworks and Classifications," Journal of Business Models (1:1), pp. 85-105.

Fielt, E., and Gregor, S. 2016. "What's New About Digital Innovation?," Paper presented at the Information Systems Foundations (ISF) Workshop, Canberra, AU.

Foss, N. J., and Saebi, T. 2017. "Fifteen Years of Research on Business Model Innovation: How Far Have We Come, and Where Should We Go? ," Journal of Management (43:1), pp. 200-227.

Govindarajan, V., and Trimble, C. 2005. Ten Rules for Strategic Innovators: From Idea to Execution. Boston, MA: Harvard Business Review Press.

Govindarajan, V., and Trimble, C. 2010. The Other Side of Innovation: Solving the Execution Challenge. Boston, MA: Harvard Business Review Press.

Greenwood, R., Suddaby, R., and McDougald, M. 2006. "Introduction," in Professional Service Firms (Research in the Sociology of Organizations, Volume 24), R. Greenwood and R. Suddaby (eds.). Emerald Group Publishing Limited, pp. 1-16.

Günther, W. A., Rezazade Mehrizi, M. H., Huysman, M., and Feldberg, F. 2017. "Debating Big Data: A Literature Review on Realizing Value from Big Data," The Journal of Strategic Information Systems (26:3), pp. 191-209.

Hartmann, P. M., Zaki, M., Feldmann, N., and Neely, A. 2016. "Capturing Value from Big Data: A Taxonomy of Data-Driven Business Models Used by Start-up Firms," International Journal of Operations \& Production Management (36:10), pp. 1382-1406.

Katz, D. M., Bommarito, M. J., and Blackman, J. 2017. "A General Approach for Predicting the Behavior of the Supreme Court of the United States," PLoS One (12:4).

Loebbecke, C., and Picot, A. 2015. "Reflections on Societal and Business Model Transformation Arising from Digitization and Big Data Analytics: A Research Agenda," Journal of Strategic Information Systems (24:3), pp. 149-157.

Maister, D. H. 1993. Managing the Professional Service Firm New York, NY: Free Press.

Massa, L., and Tucci, C. L. 2014. "Business Model Innovation," in The Oxford Handbook of Innovation Management, M. Dodgson, D. Gann and N. Phillips (eds.). Oxford, UK: Oxford University Press, pp. 420-441.

McAfee, A., and Brynjolfsson, E. 2017. Machine, Platform, Crowd: Harnessing Our Digital Future, (1 ed.). New York, NY: W. W. Norton \& Company.

Newell, S., and Marabelli, M. 2015. "Strategic Opportunities (and Challenges) of Algorithmic DecisionMaking: A Call for Action on the Long-Term Societal Effects of 'Datification'," The Journal of Strategic Information Systems (24:1), pp. 3-14.

Pavlou, P. A., and El Sawy, O. A. 2010. "The "Third Hand": It-Enabled Competitive Advantage in Turbulence through Improvisational Capabilities," Information Systems Research (21:3), pp. 443-471.

Schüritz, R., Seebacher, S., Satzger, G., and Schwarz, L. 2017. "Datatization as the Next Frontier of Servitization: Understanding the Challenges for Transforming Organizations," in Proceedings of the 38th International Conference on Information Systems (Icis 2017). Seoul, South Korea.

Westerman, G., Bonnet, D., and McAfee, A. 2014. Leading Digital: Turning Technology into Business Transformation. Boston, MA: Harvard Business Review Press.

Wixom, B. H., and Ross, J. W. 2017. "How to Monetize Your Data," Sloan Management Review (58:3), pp. $10-13$.

Woerner, S. L., and Wixom, B. H. 2015. "Big Data: Extending the Business Strategy Toolbox," Journal of Information Technology (30:1), pp. 60-62.

World Economic Forum. 2017. "Digital Transformation Initiative: Professional Services Industry," World Economic Forum, Geneva.

\section{Copyright}

Copyright: Erwin Fielt, Peter Westerveld, Kevin Desouza and Guy Gable (C) 2018. This is an openaccess article distributed under the terms of the Creative Commons Attribution-NonCommercial 3.0 Australia License, which permits non-commercial use, distribution, and reproduction in any medium, provided the original author and ACIS are credited. 